\title{
INTUBATION STUDIES OF THE HUMAN SMALL INTESTINE. XXI. A METHOD FOR MEASURING INTRA-LUMINAL PRESSURES AND ITS APPLICATION TO THE DIGESTIVE TRACT ${ }^{1}$
}

\author{
By W. O. ABBOTT, H. K. HARTLINE, J. P. HERVEY, F. J. INGELFINGER, \\ A. J. RAWSON, AND L. ZETZEL \\ (From the Gastro-Intestinal Section (Kinsey-Thomas Foundation) of the Medical Clinic and \\ the Johnson Foundation for Medical Physics, Hospital of the University \\ of Pennsylvania, Philadelphia)
}

(Received for publication August 31, 1942)

\section{INTRODUCTION}

The measurement of the gradient of intraluminal pressure within the digestive tract is of fundamental physiological importance because, in any hollow tube, fluid will flow from an area of high pressure to an area of low pressure, and we cannot fully understand the flow till the pressures are known. The clinical importance of intraluminal pressure measurements in hollow viscera is well exemplified by the syndromes of hyperand hypotension in the cardiovascular system. These disorders were recognized only after the development of an instrument of precision for their detection. This report deals with the development of such an instrument, suitable for use within hollow viscera, and with the results of its application to the digestive tract.

While numerous individual observations on the intra-gastric pressure, and occasionally on the intra-intestinal pressure, have been made with varying degrees of accuracy, it was not till Brody, Werle, Meschan, and Quigley (1) devised an optical recording system in 1940 that an attempt to obtain pressure gradients on animals was successful. Our attempt has been to do the same on man.

The requirements of an acceptable method are: (1) the pressure-sensitive elements must be small enough to be swallowed by the patient without discomfort and to be passed readily to any desired location, as checked fluoroscopically; (2) the instrument must be simple to calibrate in terms of absolute pressure, and capable of responding to small changes, of the order of $5 \mathrm{~mm}$. of water; (3) it must provide simultaneous records of the

${ }^{1}$ Aided by a grant from the Smith, Kline and French Laboratories. pressure at several locations in the tract; (4) the determinations, if not made continuously, must be sufficiently frequent to record all significant fluctuations; (5) the pressure-sensitive elements must measure the average hydrostatic pressure in their vicinity, and must not be subject to error caused by contact with the gut wall or small pieces of solid contents; (6) the device must not cause either obstruction or mechanical stimulation. The instrument to be described is capable of meeting all these requirements.

\section{PRINCIPLE OF THE METHOD}

The principle of the method depends on the closure of an electrical contact by a flexible diaphragm when the pressures on the two sides of the diaphragm are made equal. We have mounted the diaphragm in the wall of a hollow cylindrical brass capsule which is attached to a length of rubber tube. Through the tube, fine insulated wires are led to the contacts, one of which is stationary, the other being carried on the flexible diaphragm but so adjusted that the two contacts just touch when both sides of the diaphragm are exposed to equal pressures. When the capsule and tube have been swallowed, a known pressure applied to the inside of the capsule by way of the tube is varied until the electrical contact is just closed by the diaphragm. The value of this pressure is then equal to that in the lumen of the gut in the vicinity of the capsule. It is clear that any number of similar capsules may be attached to the same rubber tube at intervals along its length. The pressure in the gut at each of these capsules is then determined separately, by reference to the appropriate electrical circuit, and the determinations are repeated as often as may be necessary.

This procedure may be made entirely automatic. 
The known pressure is caused to vary in a cyclic manner by means of a motor-driven reciprocating pump over a range from less than atmospheric to some value considerably in excess of the greatest pressure expected in the intestine. Evidently at two points in its cycle of variation, the known pressure will be equal to the unknown, and the equality of the two can be indicated by either the opening or the closing of the contacts. The pump is arranged to carry a pen in synchronism with the piston back and forth above a strip of record paper. This pen is actuated by an electromagnet which, through suitable intervening circuits, operates at each closing or opening of the capsule contacts, thus printing a dot on the paper when the known pressure is equal to the unknown. The position of the dot printed on the paper is thus directly related to the pressure in the gut in the vicinity of the capsule. The paper is advanced by a feed mechanism and the series of dots form a semi-continuous record of the unknown pressure. When several capsules are to be used, their respective pens are filled with different colored inks so that the individual tracings may be readily identified even though they overlap on the record (Figure 1).

The rate at which the pump operates is determined by the desired time resolution and would ultimately be limited by the velocity of the cyclic pressure wave in the connecting tube and by lag in the operation of the pens. (The latter limitation could be removed by recording photographically, or with a stylus on electrolytically-active paper of the "Teledeltos" type.)

Although the cyclicly varying pressure has been referred to above as "known," it is quite unnecessary to know its actual value, since direct calibration is easy, and indeed preferable, because it takes into account any errors due to "set" of the diaphragms and lag of the pens. It is accomplished simply by placing the capsules and their connecting tube in a closed pressure bottle connected to a water manometer.

\section{CONSTRUCTION OF THE INSTRUMENT}

We have designed and built an experimental model of the instrument in which three capsules and pens record once every two seconds. On the basis of prior work with inflated balloons, it was thought that this rate would be great enough to resolve all significant fluctuations. Unfortunately, this proved not to be the case, and it is

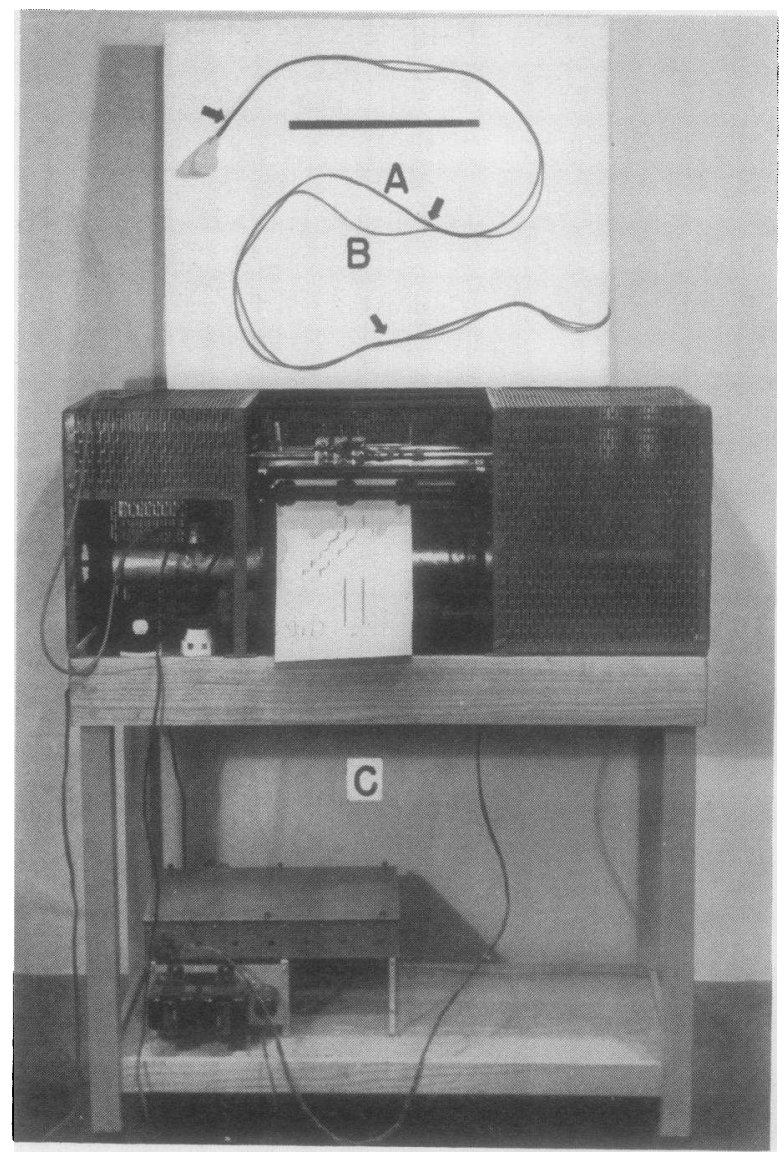

Fig. 1. Pressure Recording Apparatus

(A) Tube having three pressure-sensitive capsules whose positions are indicated by the arrows. (B) Auxiliary tube with ballon, to carry first tube down the intestine. (C) Assembly of motor-driven pump, writing pens, and amplifier.

our present opinion that the rate should be about four times as fast, that is, once every half second. The record paper moves about a third of a millimeter per second, so that consecutive dots are displaced on the time axis by about two thirds of a millimeter. This spacing is adequate and should be retained in subsequent models. While ideally it would be possible to have the instrument record the unknown pressure twice during each cycle, by using both the opening and closing of the contacts in the capsule, the lag in the magnetically operated pens, which amounted to about 1 per cent of the cycle duration, slightly displaced the dots printed on the downstroke from those printed on the upstroke. This difficulty can be avoided, but the added complication was not deemed warranted, and the machine was arranged to print only on the closure of the capsule contacts.

The pressure capsules are hollow brass cylinders, approximately $5 \mathrm{~mm}$. in diameter and $26 \mathrm{~mm}$. in length. The longitudinal section is shown in Figure 2. The 


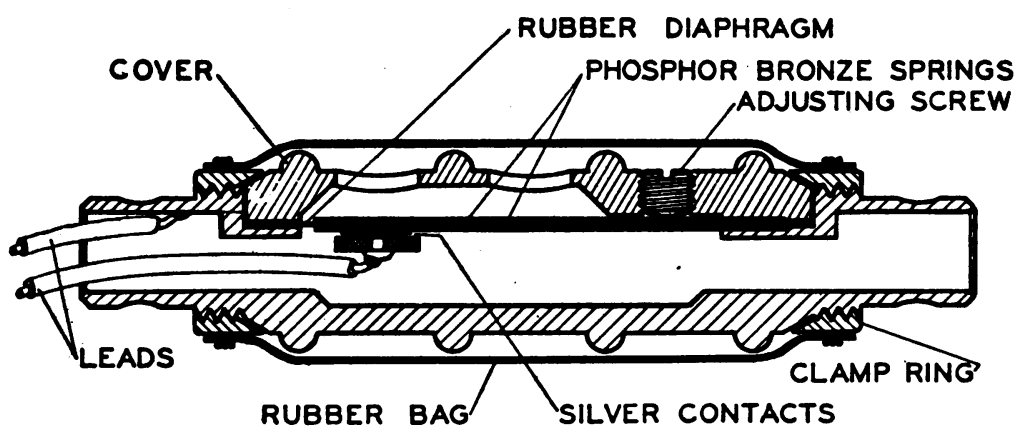

Fig. 2. Scale Drawing of Pressure-Sensitive Capsule

Overall length $26 \mathrm{~mm}$.; diameter approximately $5 \mathrm{~mm}$.

central part is milled out to form a flat seat for the diaphragm cover which is cut from thin rubber. The diaphragm is held in place by a mating cover secured by the two clamp rings. It is reinforced by two phosphorbronze strips 0.005 inch thick by 0.093 inch wide. One of these strips is soldered at one end to the body of the capsule and carries at its other end the moving contact. The other strip is soldered at one end to the cover, and is acted on by the adjusting screw, in order that the contacts may be set just to touch each other when both sides of the diaphragm are exposed to the same pressure. The stationary contact is mounted in a small bakelite strut which is cemented in the bore of the capsule body. It is of course necessary to make sure that there is a free passage through the bore for the cyclic pressure wave as well as for the fine wires from other capsules. Actually two wires from each capsule to the recording instrument are not needed, as the capsule bodies are all connected to the grounded side of the circuit. The external slack bag is also made of thin rubber, and serves to keep intestinal contents from entering the perforations in the cover and mechanically interfering with the operation of the diaphragm. The corrugated surface of the brass parts is necessary to prevent the bag from sealing the holes in the cover, thus causing false pressure indications.

The electrical system needed for indicating closure of the contacts might be very simple in the event that nonautomatic measurements were to be made. It might consist merely of a high-resistance voltmeter in series with a dry cell, with the addition of a selector switch if several capsules were to be used. However, in the automatic recording device, an electromagnet must be actuated, and the contacts in the capsule cannot themselves control the magnet current, because, first, the pen must bear against the moving record paper for only a brief period of time whose length should be independent of the duration of closure of the capsule contacts; second, the current necessary to actuate the magnet would cause arcing at the contacts with subsequent erratic operation; third, the transient voltages occurring at the interruption of the magnet current would introduce some hazard to the patient.

For these reasons, suitable vacuum-tube circuits are employed between each capsule contact and its respective pen magnet. Briefly, these consist of a high-mu triode, such as the type $6 \mathrm{SF} 5$, coupled to a pentode, such as the type $6 \mathrm{~F} 6$, through a parallel resonant circuit, blocking condenser, and grid resistor; the anode circuit of the pentode includes the pen magnet, and the effective output resistance of the circuit is increased by negative feedback methods to improve the speed of the pen. Normally, both tubes draw current from the supply, but when the contact in the capsule closes, due to the equalizing of the pressures on opposite sides of the diaphragm, the grid of the triode becomes sufficiently negative to cut off the plate current. As a consequence, there is a large transient voltage developed across the parallel resonant circuit. This voltage is in a direction to produce a large increase in the plate current of the pentode, causing the magnet to draw the pen towards the paper. The constants are so chosen that the resonant circuit is somewhat underdamped, and the duration of the transient is long enough to give adequate acceleration to the pen; but due to the underdamping, the magnet current actually falls below the quiescent value before returning to normal, thus giving a decelerating effect just before the pen hits the paper.

As the voltage necessary to over-bias the high-mu triode is only five or six, and as the impedance of the input circuit can be made as high as half a megohm, the contacts in each capsule have to control a current of only about ten microamperes, so that no arcing or erosion can occur. Furthermore, potentials of the order of five volts introduce no hazard to the patient, even in the event of extensive failure of insulation in the capsules. The pump, recorder, and low side of the electrical circuit are connected to ground as a safeguard against insulation failure in either the pump motor or the rectifier transformer supplying the vacuum tubes.

The pens are brass tubes about $0.5 \mathrm{~mm}$. inside diameter and $1 \mathrm{~cm}$. long, soldered into tubular ink reservoirs 2 $\mathrm{mm}$. in diameter and $1.5 \mathrm{~cm}$. long. In each pen there is a central brass wire whose height in the bore can be adjusted to regulate the delivery of ink. The magnetic system consists of the frame, coil, armature, and spring of a standard Dunn "midget" relay. The pen is attached to the armature by a spring hinge and moves axially in a loose guide on the coil frame. The assembly of pen and 
magnet is mounted on a bar which travels with, and parallel to, the piston of the pump.

The pump consists of a brass cylinder with a leather cup-washer piston, driven by a motor with built-in reduction gears. The length of stroke (8 inches) was chosen to give the desired length of scale on the record, since pens and piston move the same distance. The ratio of displacement volume to total clearance volume is determined by the range of pressure to be measured. The average pressure in the system is maintained equal to atmospheric by a capillary leak.

The paper feed mechanism is driven from the pump shaft through a worm gear. and chain-sprocket. To hasten drying of the ink a tubular electric heater irradiates the entire width of the paper.

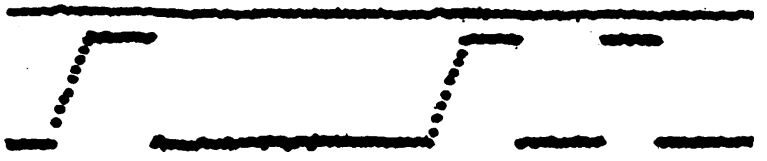

Fig. 3. Sample Record in Which the Pressure Was Altered on One Capsule Only

This shows that the response of the other units is entirely independent of changes applied to the first.

In Figure 3 are tracings recorded with three pressuresensitive capsules in operation. At the beginning of the record, all three capsules were in air. One of them (lower tracing) was then slowly immersed in water to a depth of $14 \mathrm{~cm}$., and after several seconds removed suddenly. The third time it was immersed suddenly to the same depth, and then removed. This record shows the constancy of the curves traced under unvarying pressure, and the reliability with which changes in pressure are recorded. It also shows the independence of the recording channels. A typical calibration record is shown in Figure 4. All three of the capsules were placed in a pressure bottle and covered by $2 \mathrm{~cm}$. of water. The pressure in the bottle was then adjusted to the levels indicated on the record, with the help of a water manometer, and short tracings were recorded at each level. The reliability of the base line (atmospheric pressure $+2 \mathrm{~cm}$. of water) before and after the calibration is to be noted. The calibration curves obtained from this record for each recording channel are shown in Figure 5. Because of the small range of pressures, they are nearly linear; theoretically, they are small portions of hyperbolas.

\section{RESULTS}

Fourteen observations have been carried out on nine subjects. The total recording time for the group was $281 / 2$ hours with either one, two, or three capsules in action simultaneously. Of the

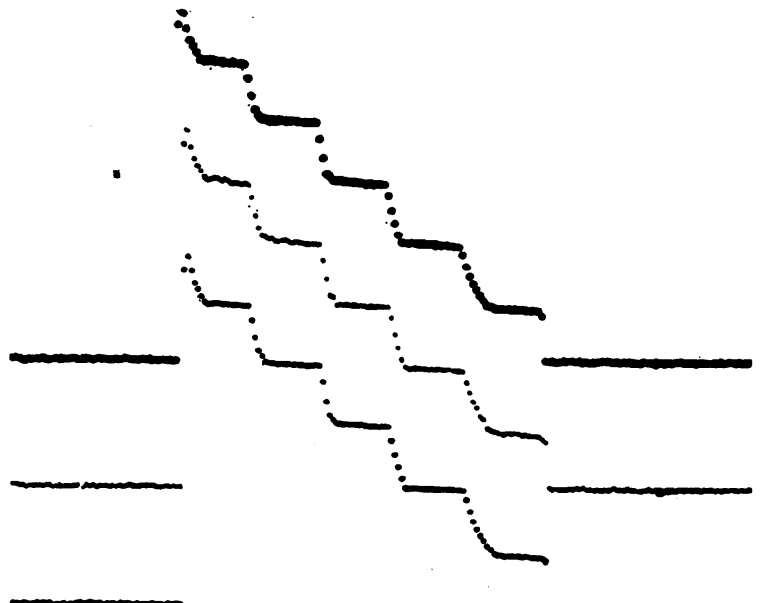

Fig. 4. Calibration Record

Time reads from left to right. All three capsules in pressure bottle are under $2 \mathrm{~cm} . \mathrm{H}_{2} \mathrm{O}$. Pressure was suddenly increased to a high value. By a controllable leak on the bottle, the pressure was then allowed to subside to $50 \mathrm{~cm} . \mathrm{H}_{2} \mathrm{O}$, where it was held for about half a minute, and then dropped successively to $40,30,20$, and $10 \mathrm{~cm} . \mathrm{H}_{2} \mathrm{O}$ to give a step-like calibration. Note that the base-line to which the trace returns is the original $2 \mathrm{~cm} . \mathrm{H}_{2} \mathrm{O}$.

nine subjects, four were normal individuals whose good health was substantiated by a history, a complete physical examination, a gastric analysis, and a gastro-intestinal fluoroscopy. Each was used twice. The remaining five subjects were patients

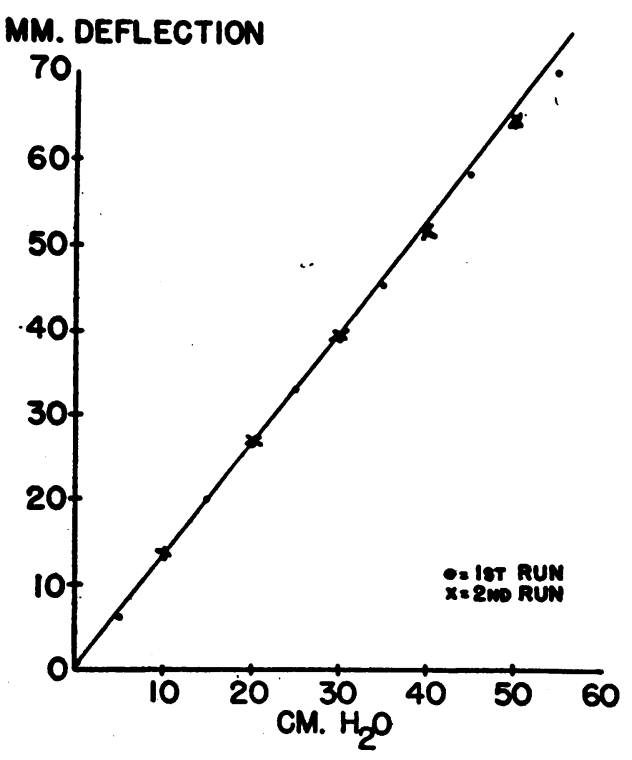

Fig. 5. The Calmbation Curve 
with either no digestive disorders or a diagnosis of a functional indigestion, arrived at by exclusion after a thorough study in the hospital. Each experiment was conducted with the subject lying upon the fluoroscopic table for frequent observation.

From these records typical periods were selected for detailed analysis. Figure 6 shows a coincident jejunal pressure record and a balloon record. The intra-luminal pressures (A) show characteristics typical of all our records, viz. (1) a basal pressure of 8 to $10 \mathrm{~cm}$. of water, and (2) phasic rises in pressure, in this case to $30 \mathrm{~cm} . \mathrm{H}_{2} \mathrm{O}$ or less. In contrast, the balloon record which in a rough way is a measure of the capacity of the gut lumen over a limited area shows a pattern of far greater variability indicating that not every contraction or relaxation of the intestinal musculature brings about an appreciable change in intra-luminal pressure.

Figure 7 shows an attempt to place the pressure regulating mechanism of the gut under stress. A single instrument was placed in the mid-jejunum and water was given by mouth. During the next 15 minutes, a basal pressure averaging $11.2 \mathrm{~cm}$. of $\mathrm{H}_{2} \mathrm{O}$ was maintained. A succession of phasic pressure waves, gradually increasing in intensity till levels of 35 to $55 \mathrm{~cm}$. of $\mathrm{H}_{2} \mathrm{O}$ were reached, now appeared. The true mean pressure during this period was $13 \mathrm{~cm} . \mathrm{H}_{2} \mathrm{O}$.

A balloon just distal to the recorder was now blown up to form an obstruction to flow. Water was injected proximal to the balloon until the pressures obtained represented those occurring above an acute artificial intestinal obstruction. Waves of pressure, equalling in their intensity those of the unobstructed gut but more prolonged in their duration, now appeared. From the 25th to the 40th minute of the experiment, the average basal pressure was $15.7 \mathrm{~cm} . \mathrm{H}_{2} \mathrm{O}$ and the mean pressure $20.3 \mathrm{~cm} . \mathrm{H}_{2} \mathrm{O}$.

To obliterate the waves and raise the tonus of the intestine, morphine sulphate, gr. $1 / 6$, was given subcutaneously at 59 minutes. Only one phasic wave appeared thereafter but a rise in the basal pressure to $17.8 \mathrm{~cm}$. $\mathrm{H}_{2} \mathrm{O}$ was observed during the subsequent 10 minutes.

Figure 8 represents the relation of gastric fundus, gastric antrum, duodenal cap, and distal duodenal pressures. Records from three points were simultaneously obtained. Tracings A and B show essential identity, save for slight gravity. (altitude) differences in the pressures in the two ends of the stomach. The subject had taken two glasses of a thin water-barium mixture to drink. Pressure waves affected the antrum and

\section{SIMULTANEOUS INTESTINAL PRESSURE \& BALLOON RECORDS}
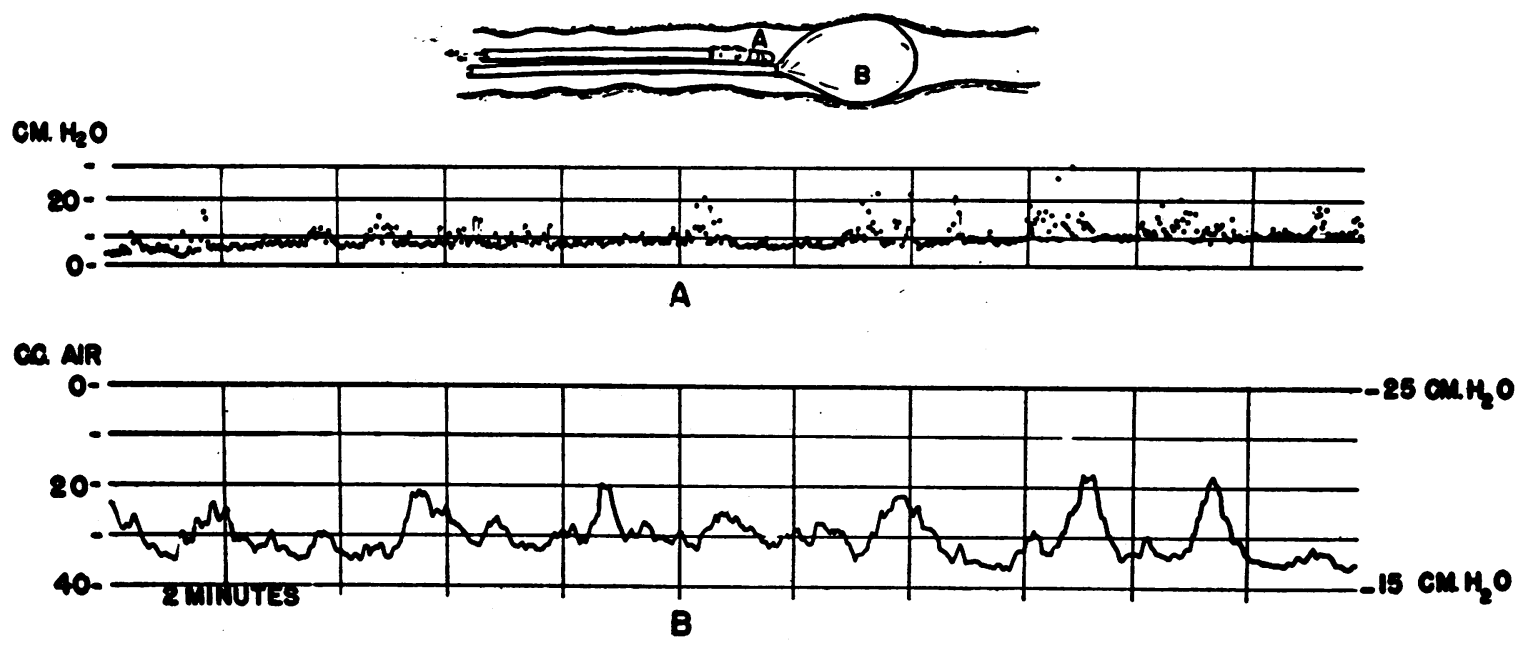

Fig. 6. Comparison of a Balloon Record and a Pressure Record

(A) The intra-luminal pressures and the location of the instrument. (B) The balloon tracing. It is obvious that the two do not coincide. 


\section{ranee of jejumal pressures}

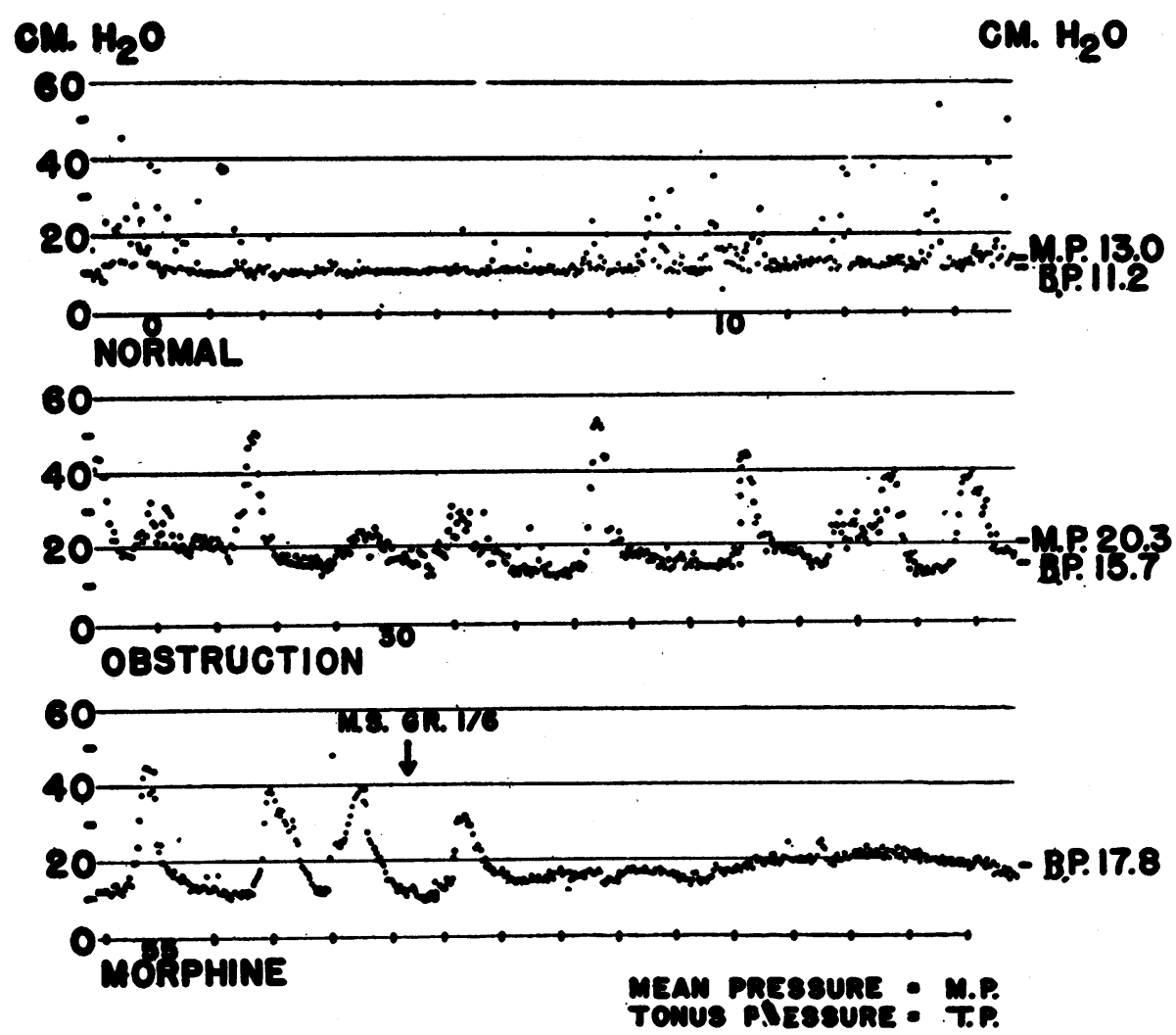

Fig. 7. Pressures Resulting Above an Artificial Mechanical Obstruction of THE JEJUNUM

the fundus alike and apparently had nothing to do with the gastric peristalsis visible by fluoroscopy. While three antral peristaltic waves per minute might reach the pylorus, these general gastric contractions might occur only once in one and a half or two minutes. Nevertheless, the appearance of high pressures in the duodenal cap coincided roughly with the peaks of intra-gastric pressure. Fluoroscopic observation of the stomach suggested that if a wave of antral peristalsis relaxed the pylorus at some time close to the height of the gastric contraction, then gastric contents entered the duodenal cap and the cap pressure rose sharply. Thus the rise in cap pressure bore an approximate rather than an exact relationship to the peak of gastric pressure and more nearly corresponded in time to the opening and closing of the pylorus, provided this occurred while the intra-gastric pressure was high enough to force the gastric contents into the duodenum.
That such was not always the case, however, is suggested by Figure 8, showing the result of moving the recorder along the intestine from positions $\mathrm{A}, \mathrm{B}$, and $\mathrm{C}$ to positions $\mathrm{B}, \mathrm{C}$, and $\mathrm{D}$. Gastric pressure now maintained an average level slightly above the duodenal, and gastric evacuation occurred as the pylorus opened, without slowly recurring rises in intra-gastric pressure being noticeable.

Figure 9 shows the simultaneous pressure changes at three widely separated points in the upper small intestine of a patient with a kidney stone, whose "reflex" gastro-intestinal disturbances, chiefly belching, nausea, distention, and abdominal cramps, led to a tentative diagnosis of intestinal obstruction by the admitting officer. In the mid-duodenum, the basal pressure and mean pressure were respectively $11.8 \mathrm{~cm} . \mathrm{H}_{2} \mathrm{O}$ and 14.8 $\mathrm{cm} . \mathrm{H}_{2} \mathrm{O}$. In the upper jejunum, these pressures were $13.8 \mathrm{~cm} . \mathrm{H}_{2} \mathrm{O}$ and $15.2 \mathrm{~cm} . \mathrm{H}_{2} \mathrm{O}$, respectively, 
and in the mid-jejunum, they were still higher, basal pressure $14.6 \mathrm{~cm} . \mathrm{H}_{2} \mathrm{O}$ and mean pressure $16.1 \mathrm{~cm} . \mathrm{H}_{2} \mathrm{O}$.

\section{DISCUSSION}

The distribution of intra-luminal pressures in the digestive tract produces the flow of contents and, in all probability, accounts for most digestive symptoms, since stretching the gut is a major cause of intestinal pain. Before we can begin to define the normal limits of gastro-intestinal pressures, however, a great deal more work must be done. Hidden sources of error especially must be discovered and eliminated. In the past, for instance, much work has been invalidated by a failure to differentiate between the pressure produced by the contraction of the bowel wall upon its fluid contents and that produced by the contraction of the wall upon a balloon. Pressures transmitted by a balloon are not only modified by

GASTRO-DUODENAL PRESSURE AND FLOW .

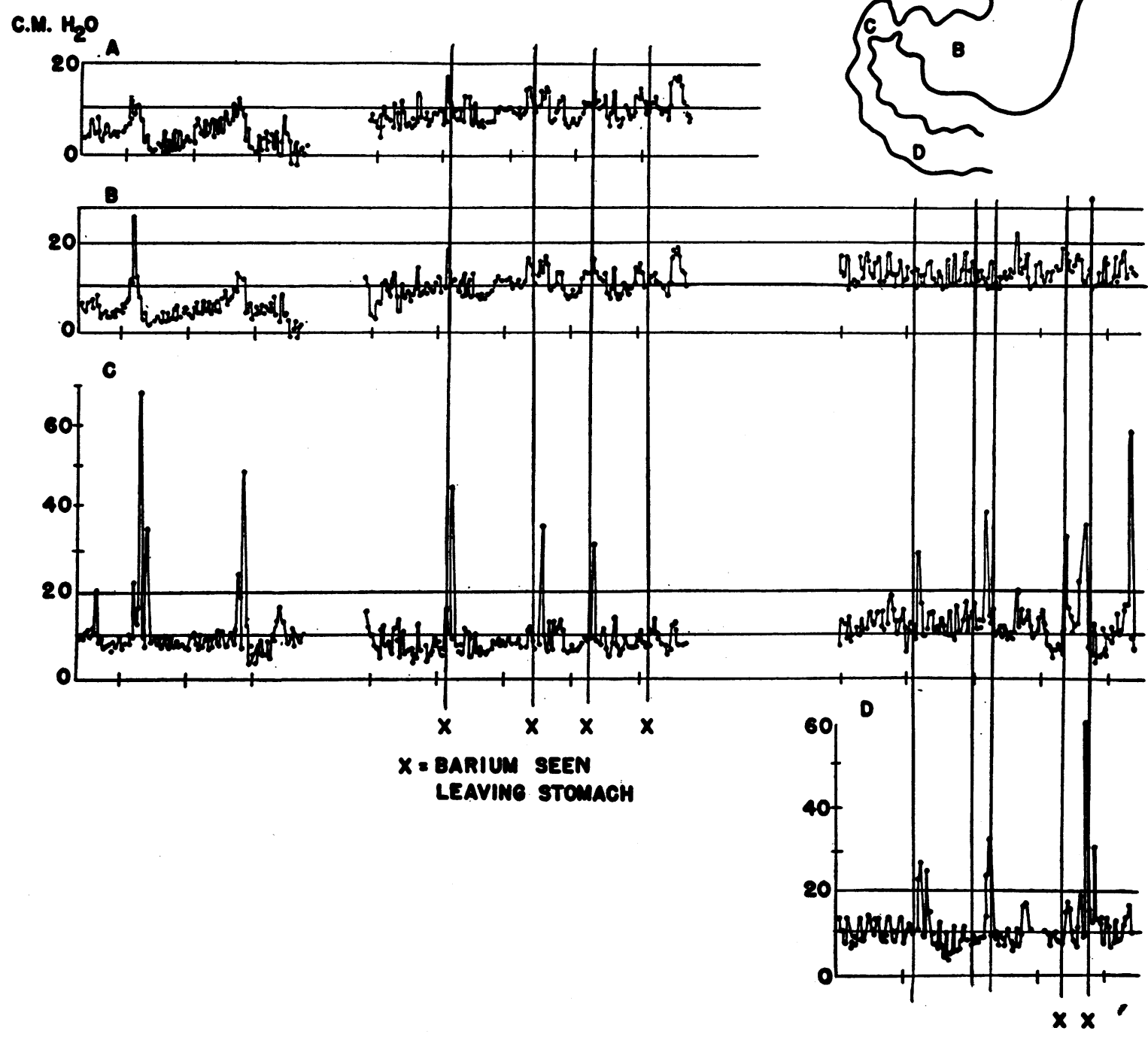

Fig. 8. Correlation of Pressures Recorded at Three Points in the Gastro-Duodenal Region Simultaneously With the Flow of Bartum from the Stomach to the Duodenum 


\section{simultaneous small intestinal pRessures}
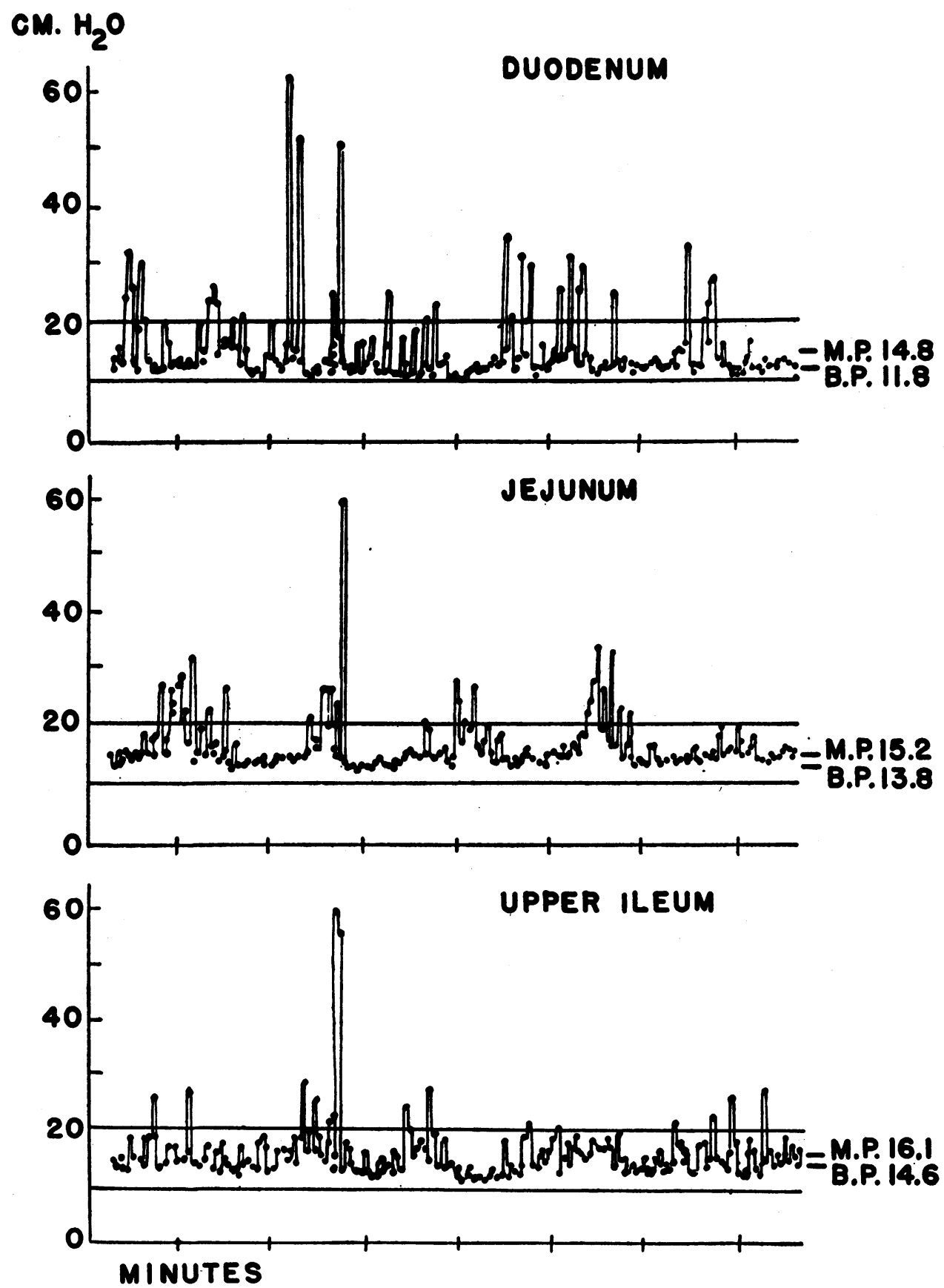

Fig. 9. Pressures Recorded from a Case of "Reflex" Vomiting and Distention

the elasticity of the rubber but by the inability of the balloon content to escape from the area involved in the contraction. For this reason, pressures recorded by a balloon system may grossly exaggerate the true intra-luminal pressure developed under normal circumstances which allow the content of a contracting segment to move downstream. It is also obvious that the intra- 
luminal pressure is the sum of the pressure of the abdominal wall upon its contents, the pressure of the viscera upon one another, and the intrinsic pressure of the intestinal wall upon its content. The altitude of the recording units must be known, since within the stomach of a standing patient, the pressure will be as much higher in the antrum than in the pylorus as a water column of comparable height. When the subject is supine, with both recorders at the same altitude, the pressure at opposite ends of the stomach may be equal.

We feel that our scattered observations on man are comparable to the studies of Brody, Werle, Meschan, and Quigley et al. (2 to 5) on the dog, because vertical and horizontal fluoroscopy convinced us that the sources of error mentioned were eliminated or else equally applicable to all recorders. The same pattern of a basal pressure with superimposed phasic pressures of 30 to 60 $\mathrm{cm}$. occurs in man as in the dog, though the basal pressure in man is somewhat higher. In the mechanism of gastric emptying, some difference exists in that Quigley's dogs appeared to empty their stomach contents into the cap in response to local pressure changes in the pre-pyloric region, though he has not yet shown that the general intra-gastric pressure was not likewise elevated at these times. Our human subjects frequently emptied gastric contents when the total intragastric pressure was at or near its peak, rather than in time with pre-pyloric peristaltic contractions, many of which occurred without the expulsion of barium unless this coincided with a rise in general intra-gastric pressure. However, we have not yet been able to record the pressure in the distal antrum at the moment of contraction, as distinct from the general intra-gastric pressure. The low viscosity of our thin water-barium mixture may also play a part in rendering antral contractions incapable of isolating a pre-pyloric chamber. We incline to agree with Alvarez (6), Barclay (7), and Wilson and Irving (8) in thinking that human antral peristalsis does not partition the antrum from the rest of the stomach save under special circumstances, such as just before complete emptying of the stomach takes place.

The pressures above the artificial obstruction showing a sustained level of 10 to $18 \mathrm{~cm}$., with phasic pressures to 40 or $50 \mathrm{~cm} . \mathrm{H}_{2} \mathrm{O}$, exceed those recorded by Wangensteen (9) of 4 to 14 cm. $\mathrm{H}_{2} \mathrm{O}$, rising to 20 to $30 \mathrm{~cm} . \mathrm{H}_{2} \mathrm{O}$ in a clinical case of mechanical obstruction of more than 48 hours duration. His reading was made by thrusting a needle connected to a manometer into the distended gut at the operating table. Earlier in the patient's course, before distention took place, the intra-luminal pressure may have been higher.

The single record of a rising gradient of internal pressure in the presence of a marked functional disorder proves nothing in so far as $\mathrm{Al}$ varez' theory of intestinal gradients is concerned but is placed on record as an observation of some interest, to be interpreted only when other material of a comparable nature is obtained.

The method is accurate, free from the disturbances of pulse and respiration, and records at a frequency that is probably adequate for most purposes; but the clinical authors have found it rather like an old Swiss watch-it takes the original makers to repair it when it breaks down. The ideal instrument must be more simple.

\section{SUM MARY}

1. An instrument for recording in absolute terms the intra-luminal pressures simultaneously at multiple selected points in the human digestive tract, without obstructing the lumen, stimulating the gut locally, necessitating a fasting state, or inordinately disturbing a sick patient, has been designed.

2. Basic pressures of 8 to $10 \mathrm{~cm} . \mathrm{H}_{2} \mathrm{O}$ are present in the human small intestine.

3. Phasic pressures rising to 30 or 40 or occasionally even to $50 \mathrm{~cm} . \mathrm{H}_{2} \mathrm{O}$ occur spontaneously.

4. Placing the gut under stress, by creating an obstruction or by giving morphine, changes the extremes of intra-luminal pressures by only a few cm. of $\mathrm{H}_{2} \mathrm{O}$ but alters the pressure pattern.

5. The coincident gastric and duodenal pressures attendant on gastric emptying were observed.

\section{BIBLIOGRAPHY}

1. Brody, D. A., Werle, J. M., Meschan, I., and Quigley, J. P., Intralumen pressures of digestive tract, especially pyloric region. Am. J. Physiol., 1940, 130, 791.

2. Werle, J. M., Brody, D. A., Ligon, E. W., Jr., Read, M. R., and Quigley, J. P., The mechanics of gastric evacuation. Am. J. Physiol., 1941, 131, 606. 
3. Quigley, J. P., Werle, J. M., and Brody, D. A., The correlation of antral and bulbar pressures with fluoroscopic observations during gastric evacuation. Am. J. Digest. Dis., 1940, 7, 434.

4. Quigley, J. P., Werle, J., Ligon, E. W., Jr., Read, M. R., Radzow, K. H., and Meschan, I., The influence of fats on the motor activity of the pyloric sphincter region and on the process of gastric evacuation studied by the balloon-water manometer and by the optical manometer-fluoroscopic technics. Am. J. Physiol., 1941, 134, 132.
5. Quigley, J. P., and Meschan, I., Inhibition of the pyloric sphincter region by the digestion products of fat. Am. J. Physiol., 1941, 134, 803.

6. Alvarez, W. C., An Introduction to Gastro-Enterology. Paul B. Hoeber, Inc., New York, 1940.

7. Barclay, A. E., Practical importance of mechanics in digestion. Am. J. Roentgenol., 1938, 40, 325.

8. Wilson, M. J., and Irving, L., Pressures in stomach. Canad. M. A. J., 1931, 25, 685.

9. Wangensteen, O. H., Experimental and clinical observations relating to the management of acute bowel obstructions. Ann. Int. Med., 1939, 13, 987. 